\title{
Spinal intraosseous epidural arteriovenous fistula with perimedullary drainage obliterated with Onyx embolization: case report
}

\author{
Chang-Hsien Ou, MD, ${ }^{1}$ Hao-Kuang Wang, MD, ${ }^{2}$ Tzu-Hsien Yang, MD, ${ }^{3}$ \\ Cheng-Loong Liang, MD, PhD, ${ }^{2}$ and Ho-Fai Wong, MD ${ }^{4,5}$
}

\begin{abstract}
Departments of ${ }^{1}$ Neuroradiology and ${ }^{2}$ Neurosurgery, E-Da Hospital, I-Shou University, Kaohsiung; ${ }^{3}$ Department of Radiology, Chia-Yi Christian Hospital, Chia-Yi; ${ }^{4}$ Department of Imaging and Intervention, Chang Gung Memorial Hospital at Linkou; and ${ }^{5}$ College of Medicine and School of Medical Technology, Chang Gung University, Linkou, Taiwan
\end{abstract}

\begin{abstract}
The authors report an extremely rare case of spinal intraosseous epidural arteriovenous fistula (AVF) with perimedullary vein reflux causing symptoms of myelopathy. The intraosseous fistula tracts were completely obliterated with Onyx embolic agent, resulting in a total resolution of symptoms. The unique features of this case include the rare location of the fistula in the vertebral body and the association of the fistula with a compressive fracture. Imaging studies confirmed these hemodynamic findings and provided clarity and direct evidence regarding the association of epidural AVF formation with the vertebral compressive fracture. The authors also propose a possible disease evolution based on the previously adduced reflux-impending mechanism.
\end{abstract}

http://thejns.org/doi/abs/10.3171/2014.12.SPINE141062

KEY WORDS spinal epidural arteriovenous fistula; intraosseous; compressive fracture; myelopathy; Onyx embolization; vascular disorders

A SPINAL dural arteriovenous fistula (AVF) is the most common spinal vascular lesion, accounting for $70 \%$ of all arteriovenous shunts of the spine. ${ }^{7,10}$ In very rare situations, the fistula tract occurs extradurally between the radicular artery branches and the epidural venous plexus in a condition referred to as a "spinal epidural arteriovenous fistula." This lesion is very rare, and only a limited number of cases have been reported in the literature to date. ${ }^{1-4,8,13,15,18}$ Here we describe an extremely rare case of intraosseous spinal epidural AVF with perimedullary vein reflux causing symptoms of myelopathy. The intraosseous fistula was located in a fractured vertebral body and was totally obliterated using Onyx embolization. We present the unique imaging features of the intraosseous communications, clarify the relationship between the traumatic compressive fracture and the extradural AVF formation, and propose our pathophysiological hypothesis for such rare cases.

\section{Case Report}

History and Examination

A 57-year-old man who performed heavy labor presented with a history of T-6, T-9, T-12, and L-2 compression fractures due to occupational injuries sustained before 2005 and mild low-back pain lasting for more than 1 year. After accidentally falling from a tree in 2009, the patient experienced acute deterioration in his symptoms of low-back pain with paresthesia. His Medical Research Council Scale score for muscle strength was Grade 3 for the bilateral iliopsoas muscles, Grade 4 for the quadriceps muscles, Grade 2 for the hamstring muscles, and Grade 2 for the dorsiflexor muscles. The knee and ankle jerks were more brisk than the tendon jerks in the arms, and the plantar responses were positive. Urine retention and feces incontinence were also noted. Spinal T2-weighted MRI revealed hyperintensity and edema of the spinal cord with 
numerous abnormal dilated vessels indicating spinal dural AVF with perimedullary venous drainage (Fig. 1A and B). Spinal angiography showed an epidural AVF fed by the left T-12 intercostal artery with intraosseous fistula tracts directly connecting to the basivertebral vein and draining to the anterior internal (epidural) vertebral venous plexus with reflux into the perimedullary (intradural-extramedullary) veins (Fig. 1C and D).

\section{Treatment}

Embolization was performed via selective catheterization from the left T-12 intercostal artery into the fistula, and $0.6 \mathrm{ml}$ of Onyx LES (liquid embolic system, Covidien Ltd.) was injected over a 12-minute period. The proximal parts of the venous receptacle and each intraosseous fistula tract were totally occluded in one session, and postembolization angiography showed complete obliteration of the AVF (Fig. 2A and B).

\section{Posttreatment Course}

The patient's symptoms resolved the day after embolization, and he was able to walk with aid. Follow-up MRI 5 days later revealed the complete disappearance of abnormal cord signal intensity and the resolution of dilated vessels. Multidetector CT with multiplanar reconstruction clearly confirmed the intraosseous communication of the AVF (Fig. 3). The patient was discharged 1 week later, and rehabilitation of the bilateral lower extremities was arranged. Three- and 6-month clinical follow-ups with MRI (Fig. 2C) and 1-year digital subtraction angiography studies showed complete remission of the neurological symptoms with no abnormality or residual fistula.
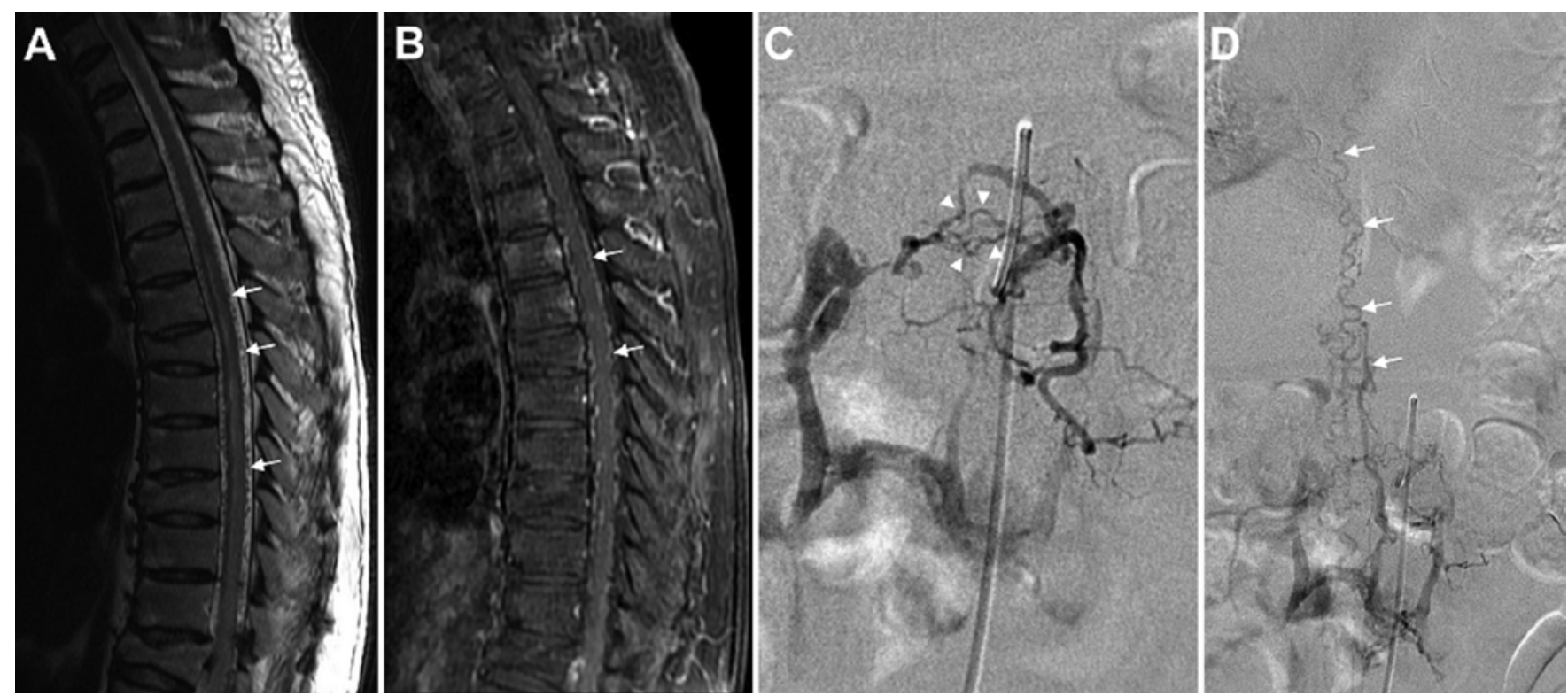

FIG. 1. Preembolization studies. Sagittal T2-weighted (A) and T1-weighted Gd-enhanced (B) MR images of the thoracolumbar spine reveal numerous dilated perimedullary abnormal vascular structures (arrows), which raise the suspicion of a spinal dural or perimedullary AVF. The high signal intensity within the spinal cord (A) indicates spinal cord edema. Early (C) and late (D) phase, anteroposterior views, with selective angiography at the left 12th thoracic intercostal artery, reveal an extradural AVF (arrowheads) draining into the basivertebral vein, the segmental vein, the intervertebral vein, and the internal plexus with reflux into the tortuous perimedullary veins (arrows). 


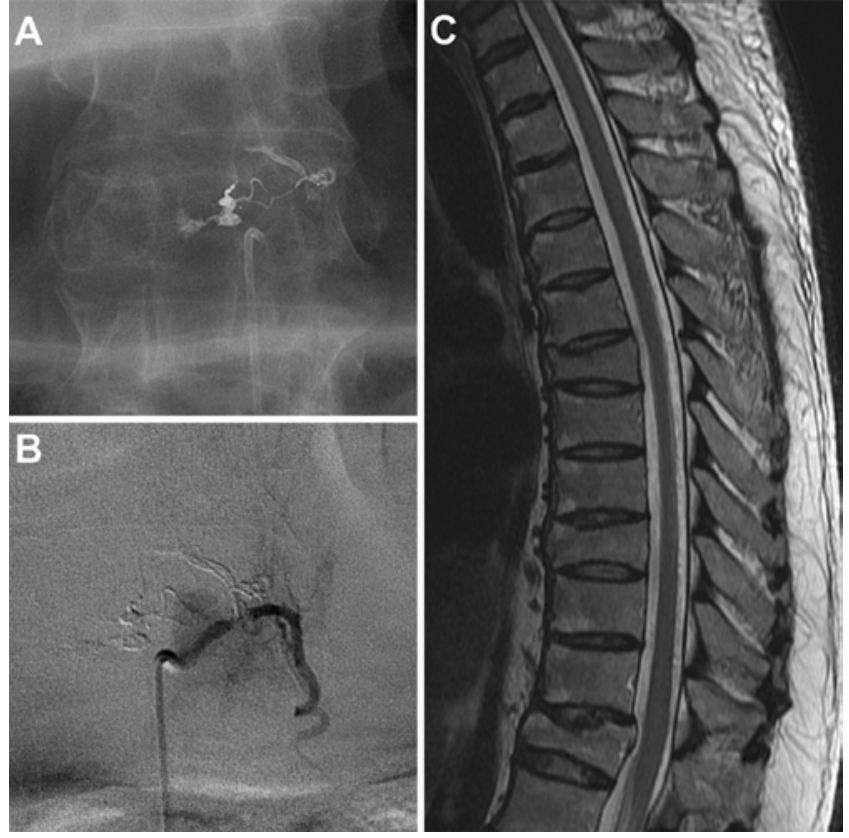

FIG. 2. Post-Onyx embolization studies. Scout film (A) and selective (B) angiograms (anteroposterior views, obtained at the left 12th thoracic intercostal artery) show total obliteration of the fistula and proximal drainage vein (basivertebral vein). A 6-month follow-up sagittal T2-weighted MR image $(\mathbf{C})$ of the thoracolumbar spine reveals the disappearance of the perimedullary venous structures and normal spinal cord signal intensity.

reflux, as in the present case, is extremely rare, with fewer than 5 cases reported in the literature., ${ }^{3,6}$ The therapeutic goal for spinal epidural AVF is to obliterate the shunt and proximal venous communication while maintaining the patency of the distal parts of the vein and proximal artery by using transarterial or transvenous embolization, direct surgery, or a combination of the two. ${ }^{1,9}$ Surgical treatment is preferred if small feeders prohibit distal catheterization or if the fistula is close to a major artery such as the anterior spinal artery. We attempted embolization via an arterial approach in our patient using the Onyx LES, which incorporates a new nonadhesive liquid embolic agent that can decrease the risk of gluing the catheter to anatomical structures and allows a more durable injection of greater volumes of agent delivered in a single session. This agent is mainly used for the treatment of cerebral dural fistulas, and some studies have used this agent for spinal dural AVFs, but only 3 reports ${ }^{12,13,15}$ have described the application of this agent for spinal epidural AVFs. A study by Silva et al. ${ }^{15}$ documented 2 cases of epidural AVF treated using Onyx embolization, but treatment failed because of incomplete occlusion of the draining vein and the risk of agent migration into the spinal artery via anastomosis. Nogueira et al. ${ }^{11}$ reported that endovascular treatment with Onyx was feasible, safe, and highly effective, as it allows more controllable penetration of the embolic agent into the fistula and draining vein.

Several interesting clinical points, unlike those in other studies, existed in our case. For example, the fistula in our case had an intraosseous course associated with compressive fracture, and imaging studies confirmed these hemodynamic findings and provided clarity and direct evidence regarding the association between epidural AVF formation and trauma (compressive fracture). Because our patient had incurred a compressive fracture before symptom exacerbation, we hypothesized that the fistula developed in the vertebral body and was fed by the left T-12 intercostal artery connecting to the basivertebral vein. At this stage, symptoms may be caused by mass effect and can be tolerated. After a period of time or following an accident, the reflux-impending mechanism may be destroyed, resulting in retrograde flow into the perimedullary vein, causing medullary venous hypertension and cord edema. In this case, we performed transarterial embolization of the completely occluded intraosseous fistula tracts and proximal drainage veins using Onyx, which incorporates an embolic agent whose use is feasible, safe, and highly

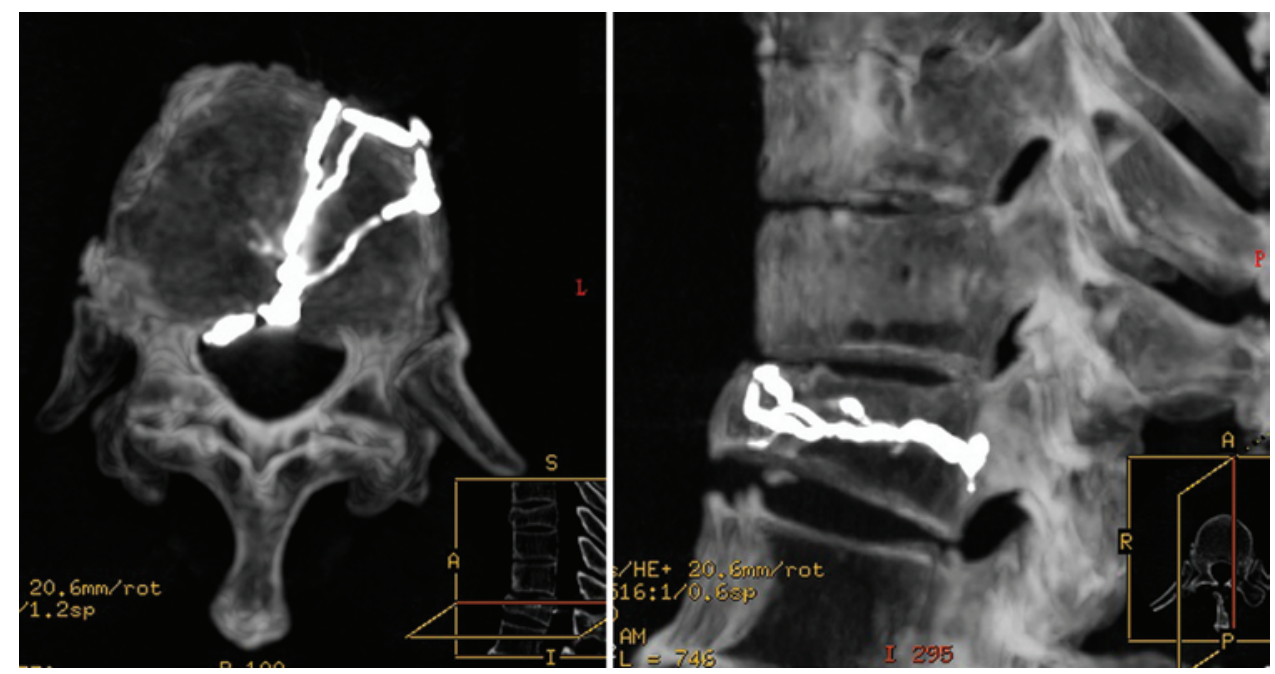

FIG. 3. Post-Onyx embolization studies. Multidetector CT scans with multiplanar reconstruction, axial (left) and sagittal (right) views, clearly confirm an intraosseous epidural fistula in the fractured T-12 vertebrae. Note the linear opacities are Onyx within the fistula and basivertebral vein. Figure is available in color online only. 
effective, allowing for good controlled penetration. In addition, it provides excellent contrast for the follow-up CT of embolized fistulas owing to high density effects.

\section{Conclusions}

Spinal intraosseous AVF draining into the epidural venous plexus with reflux into the intradural perimedullary veins and causing myelopathy is an extremely rare finding and may be associated with traumatic compressive fracture. Transarterial endovascular surgery is an effective and noninvasive therapeutic method for this vascular disease. Use of the Onyx LES is thought to be feasible and safe, allowing for good controlled penetration to achieve complete obliteration of the fistulas.

\section{References}

1. Arnaud O, Bille F, Pouget J, Serratrice G, Salamon G: Epidural arteriovenous fistula with perimedullary venous drainage: case report. Neuroradiology 36:490-491, 1994

2. Asai J, Hayashi T, Fujimoto T, Suzuki R: Exclusively epidural arteriovenous fistula in the cervical spine with spinal cord symptoms: case report. Neurosurgery 48:1372-1376, 2001

3. Chul Suh D, Gon Choi C, Bo Sung K, Kim KK, Chul Rhim S: Spinal osseous epidural arteriovenous fistula with multiple small arterial feeders converging to a round fistular nidus as a target of venous approach. AJNR Am J Neuroradiol 25:69-73, 2004

4. Cognard C, Semaan H, Bakchine S, Miaux Y, Thibault S, Sola Martinez MT, et al: Paraspinal arteriovenous fistula with perimedullary venous drainage. AJNR Am J Neuroradiol 16:2044-2048, 1995

5. Inci S, Bertan V, Cila A: Angiographically occult epidural arteriovenous fistula of the craniocervical junction. Surg Neurol 57:167-173, 2002

6. Jin YJ, Chung SK, Kwon OK, Kim HJ: Spinal intraosseous arteriovenous fistula in the fractured vertebral body. AJNR Am J Neuroradiol 31:688-690, 2010

7. Kendall BE, Logue V: Spinal epidural angiomatous malformations draining into intrathecal veins. Neuroradiology 13:181-189, 1977

8. Khaldi A, Hacein-Bey L, Origitano TC: Spinal epidural arteriovenous fistula with late onset perimedullary venous hypertension after lumbar surgery: case report and discussion of the pathophysiology. Spine (Phila Pa 1976) 34:E775-E779, 2009

9. Krings T, Mull M, Bostroem A, Otto J, Hans FJ, Thron A:
Spinal epidural arteriovenous fistula with perimedullary drainage. Case report and pathomechanical considerations. J Neurosurg Spine 5:353-358, 2006

10. Krings T, Mull M, Gilsbach JM, Thron A: Spinal vascular malformations. Eur Radiol 15:267-278, 2005

11. Nogueira RG, Dabus G, Rabinov JD, Ogilvy CS, Hirsch JA, Pryor JC: Onyx embolization for the treatment of spinal dural arteriovenous fistulae: initial experience with long-term follow-up. Technical case report. Neurosurgery 64:E197E198, 2009

12. Ramanathan D, Levitt MR, Sekhar LN, Kim LJ, Hallam DK, Ghodke BV: Management of spinal epidural arteriovenous fistulas: interventional techniques and results. J Neurointerv Surg 6:144-149, 2014

13. Rangel-Castilla L, Holman PJ, Krishna C, Trask TW, Klucznik RP, Diaz OM: Spinal extradural arteriovenous fistulas: a clinical and radiological description of different types and their novel treatment with Onyx. J Neurosurg Spine 15:541-549, 2011

14. Schroeder JM, Otto J, Thron A: Protective anti-reflux devices for spinal veins at the radicular nerve entry/exit zone: a correlative microscopic and microangiographic autopsy study. Schweiz Arch Neurol Psychiatr 144:29-30, 1993

15. Silva N Jr, Januel AC, Tall P, Cognard C: Spinal epidural arteriovenous fistulas associated with progressive myelopathy. Report of four cases. J Neurosurg Spine 6:552-558, 2007

16. Tadie M, Hemet J, Aaron C, Bianco C, Creissard P, Huard P Le dispositive protecteur anti-reflux des veines de la moelle. Neurochirurgie 25:28-30, 1979

17. Thron A, Caplan LR: Vascular malformation and interventional neuroradiology of the spinal cord, in Brandt $\mathrm{T}$, Caplan LR, Dichgans J, et al. (eds): Neurological Disorders, Course and Treatment, ed 2. Boston: Academic Press, pp 517-528, 2003

18. Willinsky R, terBrugge K, Montanera W, Wallace MC, Gentili F: Spinal epidural arteriovenous fistulas: arterial and venous approaches to embolization. AJNR Am J Neuroradiol 14:812-817, 1993

\section{Author Contributions}

Drafting the article: Ou. Critically revising the article: Ou. Reviewed submitted version of manuscript: Ou. Administrative/ technical/material support: all authors.

\section{Correspondence}

Ho-Fai Wong, Department of Imaging and Intervention, Chang Gung Memorial Hospital, No. 5 Fuxing St., Guishan Dist., Taoyuan City 333, Taiwan. email: netter.ou@gmail.com. 